\title{
Molecular analysis of the DNA gyrB gene from Myxococcus xanthus
}

\author{
Yossi Paitan, ${ }^{1}$ Neil Boulton, ${ }^{2}$ Eliora Z. Ron, ${ }^{1}$ Eugene Rosenberg ${ }^{1}$ \\ and Elisha $\mathrm{Orr}^{2}+$
}

\begin{abstract}
1 Department of Molecular Microbiology and Biotechnology, George S. Wise Faculty of Life Sciences, Tel Aviv University, Ramat Aviv, Israel

2 Department of Genetics, University of Leicester, Leicester LE1 7RH, UK
\end{abstract} Author for correspondence: Elisha Orr. Tel: +972 3 6407624. Fax: +972 3 6414138/6429377.
e-mail: orr@le.ac.uk

\begin{abstract}
DNA gyrase, an essential type II topoisomerase, mediates negative supercoiling of the bacterial chromosome, thereby affecting the processes of DNA replication, transcription, recombination and repair. The gyrB gene from the Gram-negative soil bacterium Myxococcus xanthus was sequenced. The sequence predicts a protein of $\mathbf{8 1 5}$ amino acid residues displaying significant homology to all known GyrB proteins. A 6-His-GyrB fusion protein was overexpressed in Escherichia coli and purified to near homogeneity using affinity chromatography on Ni-nitrilotriacetic acid-agarose and novobiocin-Sepharose columns. The fusion protein bound novobiocin and cross-reacted with anti-E. coli GyrB antibodies, indicating structural and functional similarities to the $E$. coli DNA GyrB. The gene was mapped to the region of the origin of replication (oriC) of $M$. xanthus.
\end{abstract}

Keywords: Myxococcus xanthus, DNA gyrase B, topoisomerase

\section{INTRODUCTION}

DNA topoisomerases play a crucial role in cellular processes that depend on the superhelical density of DNA, such as DNA replication, transcription, recombination and repair (see Orr et al., 1984; Wang, 1996). Although all known topoisomerases can relax negatively supercoiled DNA, gyrase is the only type II topoisomerase that catalyses the ATP-dependent conversion of relaxed duplex DNA to its negatively superhelical form. The functional DNA gyrase holoenzyme is a tetrameric protein $\left(\mathrm{A}_{2} \mathrm{~B}_{2}\right)$ composed of two $A$ and two $B$ subunits encoded by the gyr $A$ and gyr $B$ genes, respectively. The $90-100 \mathrm{kDa}$ GyrA subunit promotes the transient breakage and reunion of DNA, whereas the $85-95 \mathrm{kDa}$ GyrB catalyses the hydrolysis of ATP, providing the energy required for the supercoiling reaction (Wang, 1996). The enzyme is the target for two groups of antimicrobial drugs, the 4-quinolones (Crumplin, 1990) and the coumarins (Gellert et al., 1976), which inhibit the activities of GyrA and GyrB, respectively.

†Present address: Department of Molecular Microbiology and Biotechnology, George S. Wise Faculty of Life Sciences, Tel Aviv University, Ramat Aviv, Israel.

Abbreviation: NTA, nitrilotriacetic acid.

The EMBL accession number for the sequence reported in this paper is AJ000543.
The sequences of genes encoding either one or both subunits ( $g y r A$ and gyrB) of DNA gyrase from several bacteria, including Escherichia coli (Adachi et al., 1987; Swanberg \& Wang, 1987), Pseudomonas putida (Parales \& Harwood, 1990), Bacillus subtilis (Moriya et al., 1985), Haloferax sp. (Holmes \& Dyall-Smith, 1991), Staphylococcus aureus (Margerrison et al., 1992) and Haemophilus influenzae (Fleischmann et al., 1995), have been determined and analysed. The studies indicate that, in prokaryotes, both genes are structurally conserved reflecting their functional homology. Furthermore, in many bacteria analysed so far, the organization of genes around the $g y r B$ gene is highly conserved and found in the order rnpA-rpmH-dnaA$d n a N-r e c F-g y r B$, with the exception of a few, such as Borrelia burgdorferi (Old et al., 1993), Mycoplasma capricolum (Miyata et al., 1993) and H. influenzae (Fleischmann et al., 1995). The origin of chromosome replication (oriC) frequently resides in the $d n a A$ region, as observed for B. subtilis (Ogasawara et al., 1985), Salmonella typhimurium (O'Brien, 1990) and possibly P. putida (Fujita et al., 1989). In E. coli, oriC is located approximately $40 \mathrm{~kb}$ away from the $d n a A$ gene, presumably due to an inversion event (Yoshikawa \& Ogasawara, 1991). Several new bacterial type II topoisomerases have been identified (Wang, 1996). The E. coli parC and parE (topoisomerase IV) genes are homologous to the gyrA and gyrB genes, respectively, and are involved in chromosomal partition. The ParE, 
however, is smaller than the $\mathrm{GyrB}$, lacking the latter Cterminal domain.

Myxococcus xanthus is a Gram-negative, gliding, soil bacterium that feeds on proteins and peptides. It resembles the eukaryotic cellular slime moulds in its ability to form multicellular fruiting bodies during development. The formation of a fruiting body is a process by which tens of thousands of cells move, upon starvation, towards an aggregation centre to form a multicellular structure (Reichenbach, 1993). In this structure, individual rod-shaped cells differentiate into round, dormant, environmentally resistant myxospores. Genetic and biochemical evidence indicate that essential intercellular signalling occurs at multiple stages during the developmental process and that cell to cell interactions are required for proper transcriptional regulation of developmental genes.

The physical map of the $9454 \mathrm{~kb} \quad M$. xanthus chromosome was constructed using a yeast artificial chromosome (YAC) library and restriction patterns (Chen et al., 1991; He et al., 1994). The oriC of $M$. xanthus was identified on a $330 \mathrm{~kb}$ fragment (Komano et al., 1985) within the chromosome map (Chen et al., 1991; He et al., 1994; Kuspa et al., 1989), though the detailed organization of the genes around oriC is as yet unknown.

During the analysis of gene clusters in $M$. xanthus, we discovered a novel sequence homologous to bacterial gyrB genes. Here we provide evidence for the structural and functional homology of its product to other GyrB proteins.

\section{METHODS}

Bacterial strains and plasmids. The $M$. xanthus strain used in this study is ER-15, a mutant producing red pigment (Varon et al., 1992). E. coli TG1, DH1O $\beta$ and XL -1 Blue MR were used for cloning and for DNA manipulation. E. coli M15(pREP4) (Qiagen) was used for overexpression of the 6-His-GyrB fusion protein. The E. coli gyrB (temperature-sensitive) mutant LE316 (Orr et al., 1979) was utilized for the complementation assay of the $M$. xanthus GyrB in vivo. A conjugative tagged Tn1000 transposition system was applied in conjunction with the E. coli strains MH1578 and MH1599 for the sequencing as described previously (Sedgwick \& Morgan, 1994). The vectors pUC18, pUC19 (Norrander et al., 1983) and SuperCos 1 (Stratagene) were used for cloning and sequencing and the vector $\mathrm{pQE9}$ (Qiagen) was used for the expression of the 6-His-GyrB fusion protein.

Media and growth conditions. E. coli was grown in Luria broth (LB), on LB agar or in minimal media, at the required temperature, with the appropriate antibiotics as described previously by Sambrook $e t$ al. (1989). M. xanthus was grown at $32{ }^{\circ} \mathrm{C}$ in $1 \mathrm{CT}$ medium (Tolchinsky et al., 1992; Varon et al., 1992 ), or on the same medium solidified by $1.5 \%$ Bacto agar (Difco).

General DNA procedures. Standard genetic techniques, Southern blot analysis, colony hybridization, plasmid preparations and in vitro DNA manipulations were as described previously by Sambrook et al. (1989). The isolation of total DNA from $M$. xanthus has been described elsewhere
(Avery \& Kaiser, 1983). Cosmid DNA and plasmid DNA templates for sequencing reactions were purified using Qiagen columns. Conjugative transposition of Tn1000 for DNA sequencing was performed as described previously by Sedgwick \& Morgan (1994).

DNA sequencing and analysis. Automated DNA sequencing was carried out on double-stranded DNA templates, using the dideoxynucleotide chain-termination method (Sanger et al., 1977), with an Applied Biosystems model 373A sequencer. The cosmid clone pPYCA111 (a recombinant cosmid containing the $g y r B$ region) was subcloned into the vectors pUC18 and pUC19. A 3381 bp fragment derived from the cosmid pPYCA111 and the plasmid pPY05 was sequenced using the conjugative transposon mutagenesis walking system Tn1000 (Sedgwick \& Morgan, 1994). Occasional sequence gaps were filled by direct sequencing using synthetic oligonucleotide primers. Each strand of the insert was sequenced at least three times in both directions. The assembly and analysis of the primary DNA sequence data were completed using the MacVector 3.5 (International Biotechnologies) and Sequence Navigator (Applied Biosystems) software. The search for DNA and protein homologies in the databases was achieved through the BLAST (Altschul et al., 1990) and FASTA (Pearson, 1990) programs.

General protein procedures. The procedure for protein extraction from E. coli and $M$. xanthus was similar to that described previously (Ausubel et al., 1994; Sambrook et al., 1989), or to the manufacturer's instructions (Qiagen; for the purification of the 6-His-GyrB fusion protein). Proteins were separated using SDS-PAGE and stained with Coomassie brilliant blue (Laemmli, 1970). Western blot analysis was performed as described elsewhere (Ausubel et al., 1994; Sambrook et al., 1989).

Overexpression of GyrB. To construct a recombinant plasmid overexpressing a 6-His-GyrB fusion protein, a 2470 bp fragment containing the entire gyrB gene was amplified using a proof-reading DNA polymerase (ELONGASE Enzyme Mix; Gibco-BRL) from the cosmid pPYCA171 as instructed by the manufacturer. The reaction mixture was incubated at $94^{\circ} \mathrm{C}$ for $5 \mathrm{~min}$, followed by 25 cycles of: (1) denaturation at $94^{\circ} \mathrm{C}$ for $1 \mathrm{~min},(2)$ annealing at $50^{\circ} \mathrm{C}$ for $30 \mathrm{~s}$ and (3) extension at $68^{\circ} \mathrm{C}$ for $3 \mathrm{~min}$. The reaction was finally incubated for $7 \mathrm{~min}$ at $68^{\circ} \mathrm{C}$. The forward primer (P1) was $5^{\prime} \mathrm{CGGGATCCATG-}$ GAAAAGACCCCCGCTACC 3', in which a BamHI site (underlined) was incorporated so as to form an in-frame fusion immediately upstream of the first ATG initiation codon (in bold). The reverse primer (P2) was 5'GGGAAGCTTCGCGTCTTTCCGTGGGACGG3' with a HindIII site (underlined) incorporated. The PCR product was purified with the Qiagen PCR purification kit, digested with BamHI and HindIII, recovered from a $0.8 \%$ agarose gel after electrophoresis and cloned into the vector pQE9 (Qiagen). The resulting plasmid, pPYGB, carries the gyrB gene fused, inframe, to the 6-His sequence at its $5^{\prime}$ end and expressed under the control of the promoter/operator element, consisting of the $E$. coli phage T5 promoter and two lac operator sequences. pPYGB was transformed into E. coli M15(pREP4) (Qiagen) and single colonies were screened for the production of the GyrB fusion protein as instructed by the manufacturer (Qiagen) and analysed using 10\% SDS-PAGE (Laemmli, 1970).

Isolation of the GyrB fusion protein. Highly purified 6His-GyrB fusion protein (large- and small-scale preparations) was obtained by affinity chromatography on an $\mathrm{Ni}-$ nitrilotriacetic acid (NTA) resin column, following the manu- 


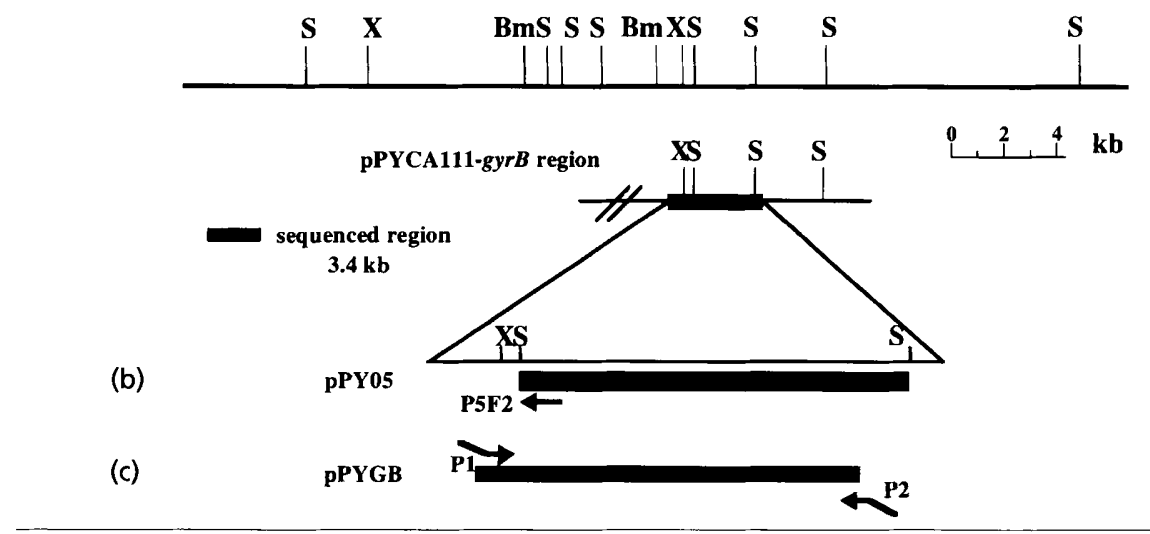

Fig. 1. Physical map of the inserts of pPYCA171 (36 kb) and the gyrB region of PPYCA111. (a) Restriction map of cosmids PPYCA171 and PPYCA111; the sequenced $3.4 \mathrm{~kb}$ fragment is indicated by a black bar on pPYCA111. (b) The $2.6 \mathrm{~kb}$ Sall fragment cloned into the plasmid PPY05, and the primer P5F2 (5'-CCATCCACGTGGATGACG$\left.A C C-3^{\prime}\right)$. (c) Primers $P 1$ and $P 2$, used for the amplification of the gyrB gene from cosmid pPYCA171 and cloning in to PPQE9. Restriction enzyme sites: S, Sall; X, Xhol; $\mathrm{Bm}, \mathrm{BamHi}$.

facturer's instructions (Qiagen), and affinity chromatography on novobiocin-Sepharose as described previously (Orr \& Staudenbauer, 1982; Staudenbauer \& Orr, 1981).

\section{RESULTS}

\section{Cloning the gyrB gene from $M$. xanthus}

In the course of constructing a cosmid library of $M$. xanthus, we analysed the recombinant cosmid pPYCA111 (Fig. 1a) and subcloned its insert into the vectors pUC18 and pUC19. Partial sequence analysis of a $2.6 \mathrm{~kb}$ Sall fragment subcloned into pUC18 (pPY05; Fig. 1b) showed that it contained a sequence homologous to various gyr $B$ genes. The $5^{\prime}$ end of the sequence was identified in the coding region of the gene and, therefore, was presumed to lack its start codons. A high stringency Southern hybridization using the $2.6 \mathrm{~kb}$ Sall fragment to probe SalI-digested chromosomal DNA indicated the existence of only one identical fragment in the chromosome of M. xanthus ER-15 (data not shown). The entire gyrB gene was consequently obtained from a cosmid library of $M$. xanthus ER-15, probed with the $2.6 \mathrm{~kb}$ SalI fragment of pPY05. The positive recombinant pPYCA171 which contained the $2.6 \mathrm{~kb}$ Sall fragment was further characterized by restriction enzyme digests (Fig. 1a).

\section{Sequence analysis of the $M$. xanthus gyrB gene}

The sequence of the $5^{\prime}$ end of the putative $g y r B$ gene was determined by using the cosmid PPYCA111 as a template and the synthetic oligonucleotide primer P5F2 (Fig. 1b). The sequence consists of $3381 \mathrm{bp}$ with a $\mathrm{G}+\mathrm{C}$ content of $66.7 \mathrm{~mol} \%$, in line with the composition of myxobacterial DNA (Shimkets, 1993). The frequency of $G+C$ at the third position of each codon in the putative ORF (see below) was found to be $89.1 \mathrm{~mol} \%$, a typical value for an ORF in organisms with a high percentage of $\mathrm{G}+\mathrm{C}$. The $M$. xanthus ORF could potentially encode a protein of 815 amino acids with a molecular mass of $89.63 \mathrm{kDa}$. A putative ribosome-binding site (AAGGA) was found $9 \mathrm{bp}$ upstream of the initiation (ATG) codon, and a putative terminator was found at the $3^{\prime}$ end.
Consensus sequences of bacterial promoters at -10 and -35 (such as TATAAT and TTGACA, respectively, for E. coli) could not be identified.

The deduced amino acid sequence of the $M$. xanthus ORF displays strong homology to all GyrB proteins. The highest score was found with the products of $S$. typhimurium gyrB $(49.8 \%$ identity, $58.1 \%$ similarity) and $E$. coli gyrB $(49 \cdot 7 \%$ identity, $58 \cdot 1 \%$ similarity) (Fig. $2)$. The identity to the smaller E. coli protein ParE was only $39.7 \%$ (48.8\% similarity). Based on the amino acid sequence homology and the predicted protein size, we concluded that this $M$. xanthus ORF is the gyrB gene.

\section{Mapping the gyrB gene on the $M$. xanthus chromosome}

A $2 \cdot 1 \mathrm{~kb}$ fragment, containing most of the gyrB gene, was amplified from the plasmid pPY05 (Fig. 1b) by PCR. This fragment was used as a probe to screen an $M$. xanthus YAC library (kindly performed by $\mathrm{H}$. Hendrix \& L. J. Shimkets, University of Georgia, Athens, GA, USA) (Chen et al., 1991; He et al., 1994; Kuspa et al., 1989). Two YAC plasmids, nos 1730 and 931 (He et al., 1994), both located within the oriC region of $M$. xanthus, hybridized to the gyrB probe. The finding that the gyrB gene of $M$. xanthus is located near the chromosomal origin of replication is compatible with similar findings in other bacteria. It is therefore feasible that the $M$. xanthus gyrB gene is part of a gene cluster containing the genes $r n p A-r p m H-d n a A-d n a N-r e c F-$ gyrB that is highly conserved in many bacteria and is frequently located close to oriC (Calcutt, 1994; Ladefoged \& Christiansen, 1994; Ogasawara et al., 1990).

\section{Overexpression of the GyrB protein}

To construct a recombinant plasmid overexpressing a 6 His-GyrB fusion protein, a 2470 bp fragment containing the entire gyrB gene (Fig. 1) was amplified by PCR from the cosmid pPYCA171 using synthetic oligonucleotides (see Methods). The forward primer, P1 (Fig. 1c), contained a Bam $\mathrm{HI}$ restriction site upstream of the first 


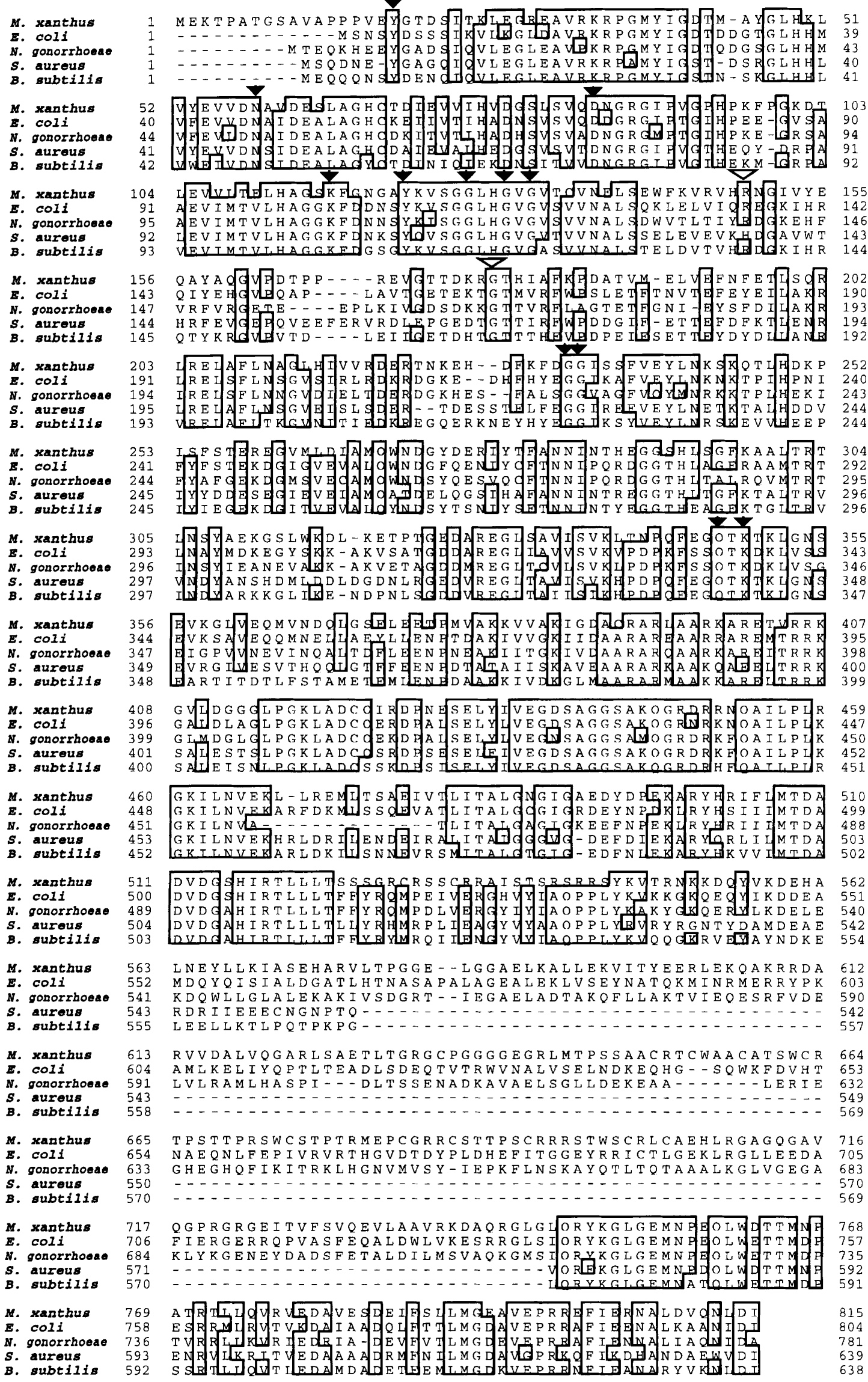


(a)

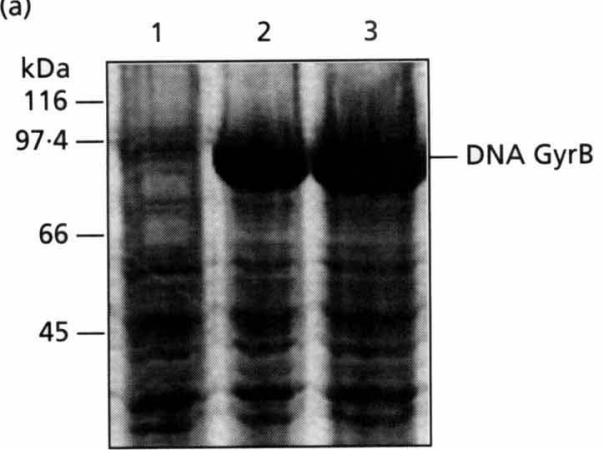

(b)

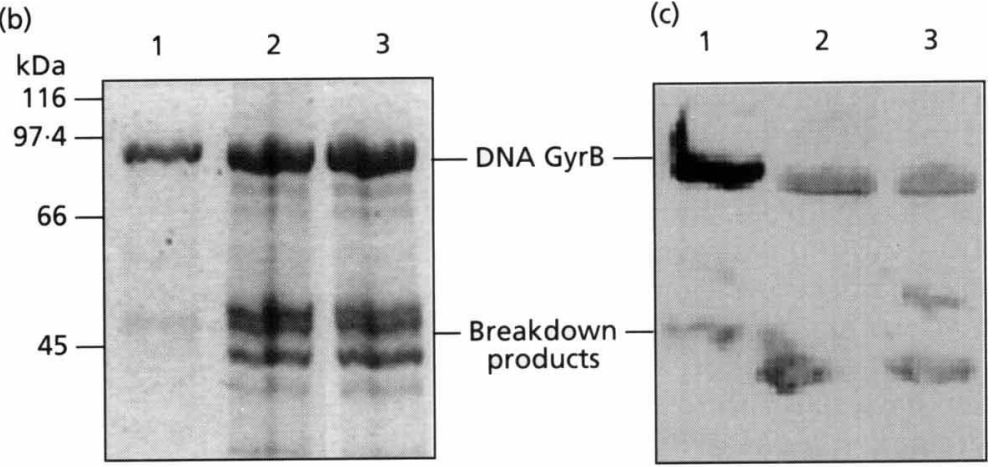

Fig. 3. Protein expression and Western blot analysis of $M$. xanthus $6-H i s-G y r B$. (a) SDS-PAGE (10\%) analysis of the M. xanthus 6-His-GyrB recombinant pPYGB expressed in E. coli strain M15(pREP4), without induction (lane 1) or with IPTG induction (lanes 2 and 3). (b) SDS-PAGE (10\%) analysis of E. coli GyrB (lane 1) and $M$. xanthus 6-His-GyrB purified by affinity chromatography on novobiocin-Sepharose (lane 2) or on Ni-NTA (lane 3) columns. (c) Western blot analysis using polyclonal antibodies raised against the $E$. coli GyrB subunit. Lane 1, E. coli GyrB; lanes 2 and 3, M. xanthus 6-His-GyrB purified on novobiocin-Sepharose or on Ni-NTA resin, respectively. Molecular mass markers are indicated.

ATG codon, whereas a HindIII site was incorporated into the reverse primer, P2 (Fig. 1c). The PCR product was digested with BamHI and HindIII and cloned into the vector $\mathrm{pQE9}$. The resulting plasmid, $\mathrm{PPYGB}$, was transformed into E. coli M15(pREP4). Ten colonies were screened for their ability to overexpress a fusion protein after induction with IPTG. The bacteria were lysed in sample buffer and their proteins were analysed using 10\% SDS-PAGE (Laemmli, 1970). All the recombinant plasmids overexpressed a protein of approximately $90 \mathrm{kDa}$ (Fig. 3a), in agreement with the calculated molecular mass of the deduced GyrB polypeptide including the six histidine residues.

\section{Purification of the 6-His-GyrB fusion protein}

The purification of the 6-His-GyrB fusion protein was achieved by either of two chromatographic procedures: (1) on Ni-NTA resin that specifically binds the six His residues and (2) on a novobiocin-Sepharose column that specifically binds DNA gyrase B (Orr \& Staudenbauer, 1982; Staudenbauer \& Orr, 1981). Total proteins were extracted from two $500 \mathrm{ml}$ cultures of the overexpressing strain after induction with IPTG, followed by the purification procedures (see Methods). The eluted fractions were analysed by $10 \%$ SDS-PAGE (Laemmli, 1970). The results presented in Fig. 3(b) demonstrate that the GyrB protein was purified by both methods. The fractions contain the $90 \mathrm{kDa}$ GyrB protein as well as smaller defined fragments of $40-50 \mathrm{kDa}$ frequently resulting from a specific proteolysis of the GyrB protein (Orr et al., 1984).

Plasmid pPYGB, overexpressing the M. xanthus gyrB, was transformed into the E. coligyrB mutant LE316 that fails to grow at $42{ }^{\circ} \mathrm{C}$ (Orr et al., 1979). The ability of $M$. xanthus GyrB protein to complement the temperaturesensitive phenotype of the E. coligyrB mutant was tested on LB agar and minimal medium plates at 32, 37 and $42{ }^{\circ} \mathrm{C}$ in the presence of different IPTG concentrations. The transformants failed to grow at the non-permissive temperature, indicating that the E. coli gyrB temperature-sensitive strain LE316 could not be complemented by the $M$. xanthus protein.

\section{Immunological cross-reactivity}

The proteins purified by the two types of chromatography were incubated with polyclonal antibodies raised against the E. coli GyrB subunit (Orr et al., 1984). As shown in Fig. 3(c), the M. xanthus protein is recognized by the antibodies, indicating that it shares antigenic properties with the E. coli protein, and provides further evidence for our conclusion that the protein is the $M$. xanthus GyrB.

\section{DISCUSSION}

We cloned and determined the complete nucleotide sequence of the gyrB gene of $M$. xanthus. The protein is functionally and immunologically similar to its $E$. coli homologue as it binds novobiocin and cross-reacts with polyclonal antibodies raised against the $E$. coli protein.

The DNA sequence data predicted a protein of 815 amino acid residues with a calculated molecular mass of $89.63 \mathrm{kDa}$, which is consistent with the size of the recombinant protein expressed in E. coli. The gene contains a putative ribosome-binding site (AAGGA) and a potential transcription terminator downstream of the stop codon but lacks promoter sequences that resemble the TATAAT and TTGACA consensus

Fig. 2. Multiple alignment of gyrase $B$ sequences from $M$. xanthus (this report), E. coli, $N$. gonorrhoeae, $S$. aureus and $B$. subtilis. Boxed letters indicate residues identical in more than three of the five organisms. The filled triangles indicate residues important in ATP binding and hydrolysis in $E$. coli. The open triangles indicate the two residues shown to be involved in coumarin resistance in $E$. coli. 
sequences at -10 and -35 , respectively. The absence of a consensus promoter, although intriguing, is not uncommon in myxobacteria. In addition, it may well be that the M. xanthus gyrB is the last gene, in an operon, transcribed from a longer polycistronic transcript. This situation would resemble that in other bacteria in which the organization of genes upstream of $g y r B$ is highly conserved. The mapping of $g y r B$ to the oriC region of the $M$. xanthus chromosome supports the idea that both its localization and organization are similar to those in other bacteria. Future analysis of our cosmid clones containing the $M$. xanthus gyrB region (pPYCA32, pPYCA40, pPYCA45 and pPYCA171) should reveal the detailed organization of genes around the oriC of $M$. xanthus and may be useful for the cloning of the M. xanthus oriC.

Comparison of the M. xanthus GyrB to that of other bacteria places it closer to the E. coli and Neisseria gonorrhoeae proteins (Fig. 2). The latter proteins have a non-conserved region of 170 amino acid residues near the $\mathrm{C}$-terminus which is absent in other bacterial GyrB proteins such as $B$. subtilis $\mathrm{GyrB}$, but present in $M$. xanthus GyrB (Fig. 2). There are several conserved regions, important for $\mathrm{GyrB}$ activity, which are present in all GyrB proteins, including the $M$. xanthus GyrB. These include the ATP- and novobiocin-binding domains, and the two consecutive glycines (at positions 220-221 in E. coli GyrB and 232-233 in M. xanthus GyrB) thought to form a flexible link between the two N-terminal subdomains (Gilbert \& Maxwell, 1994; Fig. 2).

Although theoretically possible, it is unlikely that the cloned $M$. xanthus gene is a parE homologue for the following reasons: (1) the homology of the M. xanthus protein to other GyrB proteins is higher than its homology to ParE proteins and, moreover, the homology to other known GyrB proteins extends to the Cterminal region of the $M$. xanthus protein, which is missing from ParE proteins; (2) parE products are considerably smaller in size than GyrB proteins; and (3) ParE was not identified among novobiocin-binding proteins, or proteins which are recognized by the antiGyrB antibodies.

Novobiocin inhibits non-competitively the binding of ATP to GyrB proteins. The binding site of this antibiotic, within the $\mathrm{N}$-terminal fragment of the protein, has been identified in $E$. coli through the characterization of mutant GyrB proteins resistant to the antibiotic (Ali et al., 1993). The fact that the M. xanthus GyrB strongly binds novobiocin, in a similar manner to other GyrB proteins, provides further evidence for their functional similarities. This conclusion is reinforced by the result that the M. xanthus protein is recognized by polyclonal antibodies raised against $E$. coli GyrB. The failure of the $M$. xanthus protein to complement the $E$. coli temperature-sensitive GyrB mutant LE316, at the nonpermissive temperature, suggests that the M. xanthus 6 His-GyrB fusion protein may not be able to form a functional tetramer with the E. coli GyrA subunit in vivo. It is possible that the $M$. xanthus protein is not functional at $42^{\circ} \mathrm{C}$, as $M$. xanthus does not grow at temperatures above $40^{\circ} \mathrm{C}$ (Janssen et al., 1977), or that the recombinant protein His- $\mathrm{GyrB}$ is inactive in vivo. The formation of a chimeric tetramer, although with poor activity, was previously demonstrated in vitro with the B. subtilis GyrB (Orr \& Staudenbauer, 1982). However, such a reconstituted activity has never been tested in vivo.

Finally, the overexpression and purification of the $M$. xanthus GyrB protein should facilitate the study of its structure-function relationship; the data from such a study could be exploited in the screening and identification of new potent antimicrobial agents.

\section{ACKNOWLEDGEMENTS}

We are grateful to Dr Holly Hendrix and Dr Lawrence J. Shimkets for the mapping of the $g y r B$ gene. We thank Dr S. G. Sedgwick for providing the tagged Tn1000 system and the PNACL unit at Leicester University for DNA sequencing.

This work was supported, in part, by the Pasha Gol Chair for Applied Microbiology (E.R.), the Morris and Manja Leigh Chair for Biophysics and Biotechnology (E.Z.R.), a British Council Clore Foundation Scholarship (Y.P.), a BBSRC studentship (N.B.) and grants (E.O.) from The Cancer Research Campaign (SP1937/0301) and The Wellcome Trust $(038060 / Z / 93 / Z)$.

\section{REFERENCES}

Adachi, T., Mizuuchi, M., Robinson, E. A., Appella, E., O'Dea, M. H., Gellert, M. \& Mizuuchi, K. (1987). DNA sequence of the E. coli gyrB gene: application of a new sequencing strategy. Nucleic Acids Res 15, 771-784.

Ali, J. A., Jackson, A. P., Howells, A. J. \& Maxwell, A. (1993). The $43 \mathrm{kDa}$ N-terminal fragment of gyrase B protein hydrolyses ATP and binds coumarin drugs. Biochemistry 24, 2717-2724.

Altschul, S. F., Gish, W., Miller, W., Myers, W. \& Lipman, D. J. (1990). Basic local alignment search tool. J Mol Biol 251, 403-410.

Ausubel, F. M., Brent, R., Kingston, R. E., Moore, D. D., Seidman, J. D., Smith, A. J. \& Struhl K. (editors). (1994). Current Protocols in Molecular Biology, chapter 10.10. New York: Wiley.

Avery, L. \& Kaiser, D. (1983). In situ transposon replacement and isolation of spontaneous tandem duplication. Mol Gen Genet 191, 99-109.

Calcutt, M. J. (1994). Gene organization in the $d n a A-$-gyrA region of the Streptomyces coelicolor chromosome. Gene 151, 23-28.

Chen, H., Kuspa, A., Keseler, I. M. \& Shimkets, L. J. (1991). Physical map of the Myxococcus xanthus chromosome. J Bacteriol 173, 2109-2115.

Crumplin, G. C. (editor). (1990). The 4-Quinolones. London: Springer.

Fleischmann, R. D., Adams, M. D., White, O. \& 37 other authors (1995). Whole-genome random sequencing and assembly of Haemophilus influenzae Rd. Science 269, 496-512.

Fujita, M. Q., Yoshikawa, H. \& Ogasawara, N. (1989). Structure of the dnaA region of Pseudomonas putida: conservation among three bacteria, Bacillus subtilis, Escherichia coli and P. putida. Mol Gen Genet 215, 381-387.

Gellert, M., O'Dea, M. H., Itoh, T. \& Tomizawa, J. (1976). Novobiocin and coumermycin inhibit DNA supercoiling catalysed by DNA gyrase. Proc Natl Acad Sci USA 73, $4474-4478$. 
Gilbert, E. J. \& Maxwell, A. (1994). The $24 \mathrm{kDa}$ N-terminal subdomain of DNA gyrase B protein binds coumarin drugs. Mol Microbiol 12, 365-373.

He, Q., Chen, H., Kuspa, A., Cheng, Y., Kaiser, D. \& Shimkets, L. J. (1994). A physical map of the Myxococcus xanthus chromosome. Proc Natl Acad Sci USA 91, 9584-9587.

Holmes, M. L. \& Dyall-Smith, M. L. (1991). Mutations in DNA gyrase result in novobiocin resistance in halophilic archaebacteria. J Bacteriol 173, 642-648.

Janssen, G. R., Wireman, J. W. \& Dworkin, M. (1977). Effect of temperature on the growth of Myxococcus xanthus. J Bacteriol 130, 561-562.

Komano, T., Inouye, S. \& Inouye, M. (1985). Physical mapping of a $330 \times 10^{3}$-base-pair region of the Myxococcus xanthus chromosome that is preferentially labeled during spore germination. J Bacteriol 162, 1124-1130.

Kuspa, A., Vollrath, D., Cheng, Y. \& Kaiser, D. (1989). Physical mapping of the Myxococcus xanthus genome by random cloning in yeast artificial chromosomes. Proc Natl Acad Sci USA 86, 8917-8921.

Ladefoged, S. A. \& Christiansen, G. (1994). Sequencing analysis reveals a unique gene organization in the $\operatorname{gyr} B$ region of Mycoplasma hominis. J Bacteriol 176, 5835-5842.

Laemmli, U. K. (1970). Cleavage of structural proteins during the assembly of the head of bacteriophage T4. Nature 227, 680-685.

Margerrison, E. E., Hopewell, R. \& Fisher, L. M. (1992). Nucleotide sequence of the Staphylococcus aureus gyrB-gyrA locus encoding the DNA gyrase A and B proteins. J Bacteriol 174, 1596-1603.

Miyata, M., Sano, K. I., Okada, R. \& Fukumura, T. (1993). Mapping of replication initiation site in Mycoplasma capricolum genome by two-dimensional gel-electrophoretic analysis. Nucleic Acids Res 21, 4816-4823.

Moriya, S., Ogasawara, N. \& Yoshikawa, H. (1985). Structure and function of the region of the replication origin of the Bacillus subtilis chromosome. III. Nucleic acid sequence of some 10,000 base pairs in the origin region. Nucleic Acids Res 13, 2251-2265.

Norrander, J., Kempe, T. \& Messing, J. (1983). Construction of improved M13 vector. Gene 26, 101-106.

O’Brien, S. J. (1990). Genetic Maps; Bacteria, Algae, and Proto$z o a$, pp. 2.54-2.70. Cold Spring Harbor, NY: Cold Spring Harbor Laboratory.

Ogasawara, N., Moriya, S., von Meyenburg, K., Hansen, F. G. \& Yoshikawa, H. (1985). Conservation of genes and their organization in the chromosomal replication origin of Bacillus subtilis and Escherichia coli. EMBO J 4, 3345-3350.

Ogasawara, N., Fujita, M. Q., Moriya, S., Fukuoka, M., Hirano, M. \& Yoshikawa, H. (1990). Comparative anatomy of oriC of eubacteria. In The Bacterial Chromosome, pp. 287-295. Edited by K. Drlica \& M. Riley. Washington, DC: American Society for Microbiology.

Old, I. G., Margarita, D. \& Saint Girons, I. (1993). Unique genetic arrangement in the $d n a A$ region of the Borrelia burgdorferi linear chromosome: nucleotide sequence of the dnaA gene. FEMS Microbiol Lett 111, 109-114.
Orr, E. \& Staudenbauer, W. L. (1982). Bacillus subtilis DNA gyrase: purification of subunits and reconstitution of supercoiling activity. J Bacteriol 151, 524-527.

Orr, E., Fairweather, N. F., Holland, I. B. \& Pritchard, R. H. (1979). Isolation and characterisation of a strain carrying a conditional lethal mutation in the cou gene of Escherichia coli K-12. Mol Gen Genet 177, 103-112.

Orr, E., Lother, H., Lurz, R. \& Wahle, E. (1984). Escherichia coli DNA gyrase. In Proteins Involved in DNA Replication, pp. 395-407. Edited by U. Hubscher \& S. Spadari. New York: Plenum.

Parales, R. E. \& Harwood, C. S. (1990). Nucleotide sequence of the gyrB gene of Pseudomonas putida. Nucleic Acids Res 18, 5580.

Pearson, W. R. (1990). Rapid and sensitive sequence comparison with FastP and Fasta. Methods Enzymol 183, 63-98.

Reichenbach, H. (1993). Biology of the myxobacteria : ecology and taxonomy. In Myxobacteria II, pp. 13-62. Edited by M. Dworkin \& D. Kaiser. Washington, DC: American Society for Microbiology.

Sambrook, J., Fritsch, E. F. \& Maniatis, T. (1989). Molecular Cloning: a Laboratory Manual, 2nd edn. Cold Spring Harbor, NY: Cold Spring Harbor Laboratory.

Sanger, F., Nicklen, S. \& Coulson, A. R. (1977). DNA sequencing with chain-terminating inhibitors. Proc Natl Acad Sci USA 74, 5463-5467.

Sedgwick, S. G. \& Morgan, B. A. (1994). Locating, DNA sequencing and disrupting yeast genes using tagged Tn1000. Methods Mol Genet 3, 131-140.

Shimkets, L. J. (1993). The myxobacterial genome. In Myxobacteria II, pp. 85-107. Edited by M. Dworkin \& D. Kaiser. Washington, DC: American Society for Microbiology.

Staudenbauer, W. L. \& Orr, E. (1981). DNA gyrase: affinity chromatography on novobiocin-Sepharose and catalytic properties. Nucleic Acids Res 9, 3589-3603.

Swanberg, S. L. \& Wang, J. C. (1987). Cloning and sequencing of the Escherichia coli gyrA gene coding for the A subunit of DNA gyrase. J Mol Biol 197, 729-736.

Tolchinsky, S., Fuchs, N., Varon, M. \& Rosenberg, E. (1992). Use of Tn5lac to study expression of genes required for antibiotic TA production. Antimicrob Agents Chemother 36, 2322-2327.

Varon, M., Fuchs, N., Monosov, M., Tolchinsky, S. \& Rosenberg, E. (1992). Mutation and mapping of genes involved in antibiotic TA production in Myxococcus xanthus. Antimicrob Agents Chemother 36, 2316-2321.

Wang, J. C. (1996). DNA topoisomerases. Annu Rev Biochem 65, 635-692.

Yoshikawa, H. \& Ogasawara, N. (1991). Structure and function of DnaA and DnaA-box in eubacteria : evolutionary relationships of bacterial replication origins. Mol Microbiol 5, 2589-2597.

Received 10 December 1997; revised 16 February 1998; accepted 19 February 1998. 